\title{
TESTS OF AN INNOVATIVE CONTROLLER DESIGNED TO CONTROL THE POWERED ROOF SUPPORT
}

doi:10.2478/mape-2018-0029

Date of submission of the article to the Editor: $05 / 2018$ Date of acceptance of the article by the Editor: $07 / 2018$
MAPE 2018, volume 1, issue 1, pp. 223-231
Dr inż. Dawid Szurgacz

Center of Hydraulics DOH Ltd, Poland

prof. Horst Gondek

VSB - Technical University of Ostrava, Czech Republic

\begin{abstract}
The article presents the methodology and results of tests of a prototype controller designed for the electrohydraulic control system of a powered roof support. This controller is the basic part of the developed, innovative control system. The tests were carried out on a custom-designed testing station, equipped with one section of a roof support. The aim of the research was to check the functionality and speed of the controller's response while working with the actual support section. The tested controller and the control system has a modular structure, which greatly facilitates its operation and use. Measurements of control functions were carried out on the controller connected to the electrohydraulic control block. The research mainly focused on determining the period starting from the moment of providing the signal to the moment of switching on the basic functions performed by the support section. The obtained results confirm the assumptions made. The controller's operation is very stable, and its response times are very short. It can therefore be assumed that the tested controller is correctly designed and constructed. This creates great possibilities for its practical application in the built-in system for controlling the roof support. This may be particularly important in the case of high-efficiency longwall complexes, for which wireless control of the support is planned to be used. The presented research methodology and obtained results should therefore be an important source of information in the field of testing controllers for powered roof supports.
\end{abstract}

Keywords: powered longwall system, powered roof support, control system, working parameters, visualization

\section{INTRODUCTION}

One of the biggest challenges facing the mining industry is the development, construction and implementation of a maintenance-free longwall system. Such a complex must be characterized by a high degree of automation and having an intelligent control system. Such a solution must ensure adequate efficiency, reliability and durability as well as safety for employees conducting technological operations. Practice shows that it will be virtually impossible to completely eliminate complex services in Polish conditions. However, reducing its number and moving certain activities beyond the exploitation wall might be possible. The introduction of such solutions is necessary due to the deteriorating working conditions in the mines, which results from the growing efficiency and exploitation of deposits lying in increasingly worse mining and geological conditions. The introduction of at least a partial limitation of employees' access to the most dangerous zones should improve the comfort and safety of work in mines. Such possibilities are created by properly constructed, made and controlled powered complexes. Their use can enable automation and maintenance-free implementation of many hazardous operations. It is connected with the fact that in the coming years, the Polish economy, especially in the energy area, will continue to be based on fossil fuels. Despite the decline in the share of coal in the energy balance, this fuel is still 
the key for the energy sector, stabilizing Poland's energy security and having a positive impact on the energy security of the European Union. That is why it is necessary to conduct research to develop elements that can potentially be used in new innovative powered systems. The Authors of the paper have carried out the research aimed at testing the design and construction of a new system which task is to control the powered roof support. This controller is to constitute the basic element of the new electrohydraulic control system. Effective and reliable solutions in this field are currently the most desirable products on the mining support market. Construction of this type of equipment for mining must meet a series of strict requirements which do not apply to any other systems operating in other industries. This is the result of difficult environmental conditions in which mining operations are carried out. In particular, this applies to various types of hazards occurring in mining excavations. For the control system and the entire roof support, the most threatening events are rock bursts (Szurgacz and Brodny 2018a), fire (Brodny and Tutak, 2018; Brodny et al., 2018; Tutak and Brodny, 2018; Tutak and Brodny, 2017b) and methane explosion (Brodny and Tutak, 2016, Felka and Brodny, 2018). This causes that the control systems and their individual elements must be of adequate quality and reliability. This, in turn, affects the costs of their implementation and operation. Especially now, when there is huge competition on the energy market, the economic aspect is of great importance to the mining industry []. When designing control systems, it is therefore necessary to take into account many different factors (Tutak, 2017; Brodny et al, 2018, Tutak and Brodny, 2017b).

The controller presented in the article was subjected to tests to check its effectiveness and functionality. The article discusses the methodology of the conducted research and presents a number of test results were performed for this controller. Its operation was connected with the entire control system, which was also indirectly verified during the research. The obtained results confirm the assumptions made. The controller together with the entire system worked without interruption, and the response times were very satisfactory. This creates the possibility to conduct tests in underground conditions and a wide application of the developed element. According to the Authors, the developed controller can be widely used in automated control systems for powered rood supports, which should speed up the work and implementation of this very innovative and largely intelligent solution to practice.

\section{METHODOLOGY OF RESEARCH}

The prototype controller for the powered roof support was custom-designed for the research on an innovative electrohydraulic control system. The controller consists of three circuits connected by double-row connectors. The user interface board includes a capacitive keyboard circuit and an LED signalling circuit. The capacitive keyboard consists of a controller for which 19 tactile buttons are connected in a matrix system. The keyboard buttons are arranged in two rows. Each of the buttons, due to the type of function being performed, are assigned two or four LED signalling diodes. In addition, two tow-coloured RG LEDs are located on the side edges of the board, signalling correct communication with external devices connected to the controller.

The controller's construction is adapted for free mounting in the section of a powered roof support. The main view of the controller is to control the support section in the process of operation. This is due to the fact that each section during work performs specific cycles that consist of several phases. The task of each section is quick and trouble-free execution of specific and assigned functions. All functions of the powered roof support are realized by means of hydraulic cylinders. Each hydraulic actuator is controlled by an associated system consisting usually of an electrohydraulic system connected to the controller. The view of the developed prototype driver is shown in Figure 1. The individual control functions that the support section must perform are marked as follows: 1 - sliding out the section; 2 - sliding down the section; 3 - sliding down the support's actuator; 4 - sliding down the angles strut actuator; 5 - moving the sections; 6 - moving the conveyor; 7 - sliding out the floor base 
correction actuator; 8 - sliding down the float correction actuator; 9 - sliding out of the side support actuator; 10 - sliding down the side support actuator; 11 - sliding out the side base correction actuator; 12 - sliding out the side base correction actuator; 13 - opening the staff crossing cover; 14 - closing the staff crossing cover; 15 - opening the face wall cover; $16-$ closing the face wall cover.

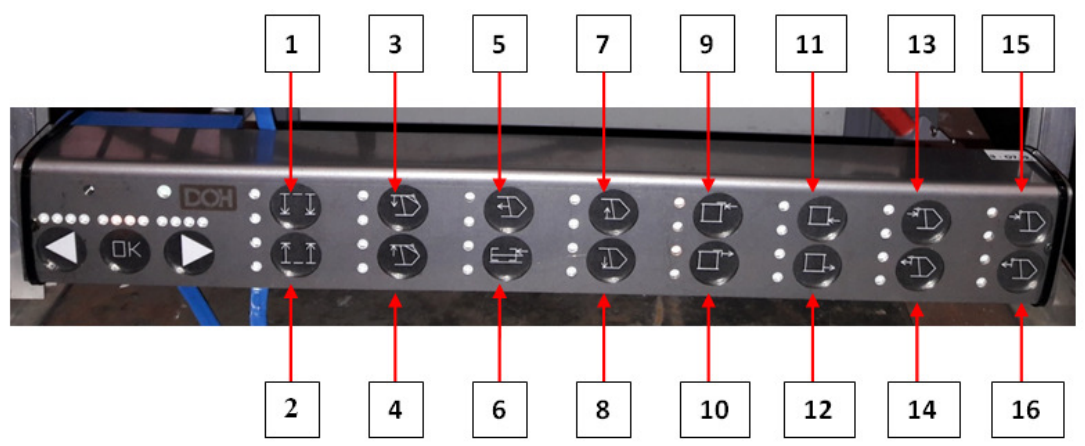

Fig. 1. A prototype controller for a powered roof support with marked functions

\section{RESULTS}

In the case studied, the prototype driver is mounted on the section from which the neighbouring section is controlled. For this reason, electrohydraulic control is included in the pilot control (adjacent). The block with solenoid valves was located in a place easily accessible during tests as well as during operation. The basic criterion determining the use of a pilot control unit for a specific type of longwall is the number of control functions in the support section. The number of functions must coincide with the number of hydraulic actuators. The manifold block has been mounted on the controlled section and can be located anywhere so that it does not hinder research. The electrohydraulic control unit consists of two separate blocks which are block of control dividers equipped with a controller and a block of executive distributors. They are connected with each other by a multi-channel cable, which is a carrier of control impulses. A prototype driver was also made for testing of an innovative system of electorhydraulic control of powered roof support. A special testing station equipped with a prototype ZRP-15/35-POz section was prepared for testing. The station is shown in Figure 2. The aim of the research was to determine the time of implementation of selected section functions that are implemented in the actual working conditions of the powered roof support. This concerned expanding and withdrawing sections (sliding down/out hydraulic legs, located between the floor bases and the canopies).

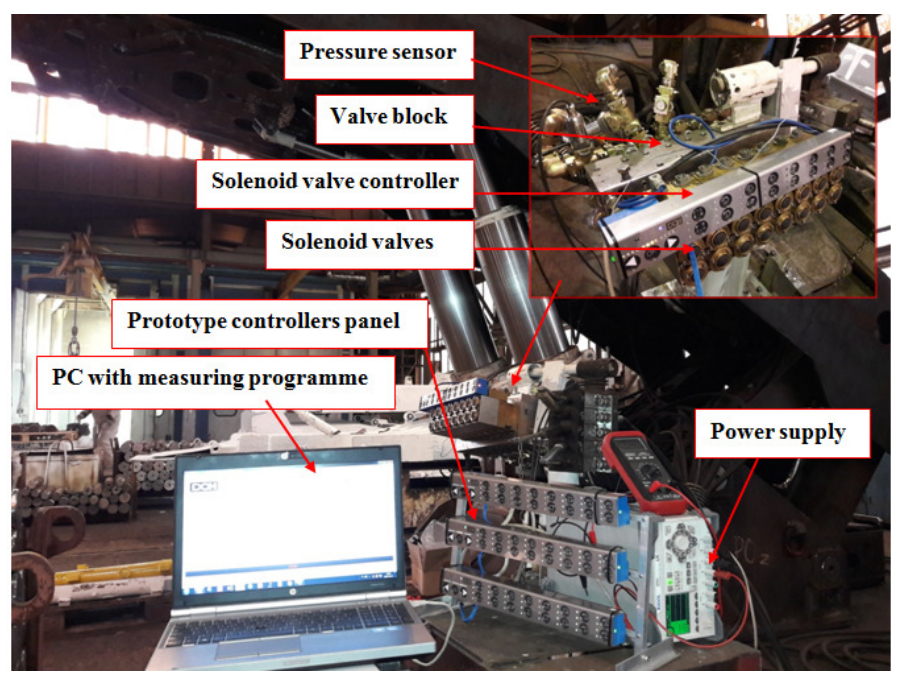

Fig. 2. Research stand for an innovative controller of the powered roof support 
The measurements included determining the time of switching the power supply on with the PWM signal and supplying the full signal to the basic functions performed by the longwall support. The measuring system developed along with the methodology was used to carry out the tests.

As a result of the tests, a number of results were obtained, which are presented in the following charts and tables. The results were grouped depending on the control function of the section. In general, the research was mainly focused was on the presentation of the measurement results of the power-up times and the determination of the delay time for the full and PWM signal. Figure 3 shows the waveforms of switch-on and power-off times for the PWM and full signal for the sliding down function performed depending on the different power source. Table 1 presents the results. The following drawings (Fig. 4, 5, 6, 7) and tables (Table 2, 3, 4, 5) present the results of tests for other functions of the powered roof support section.

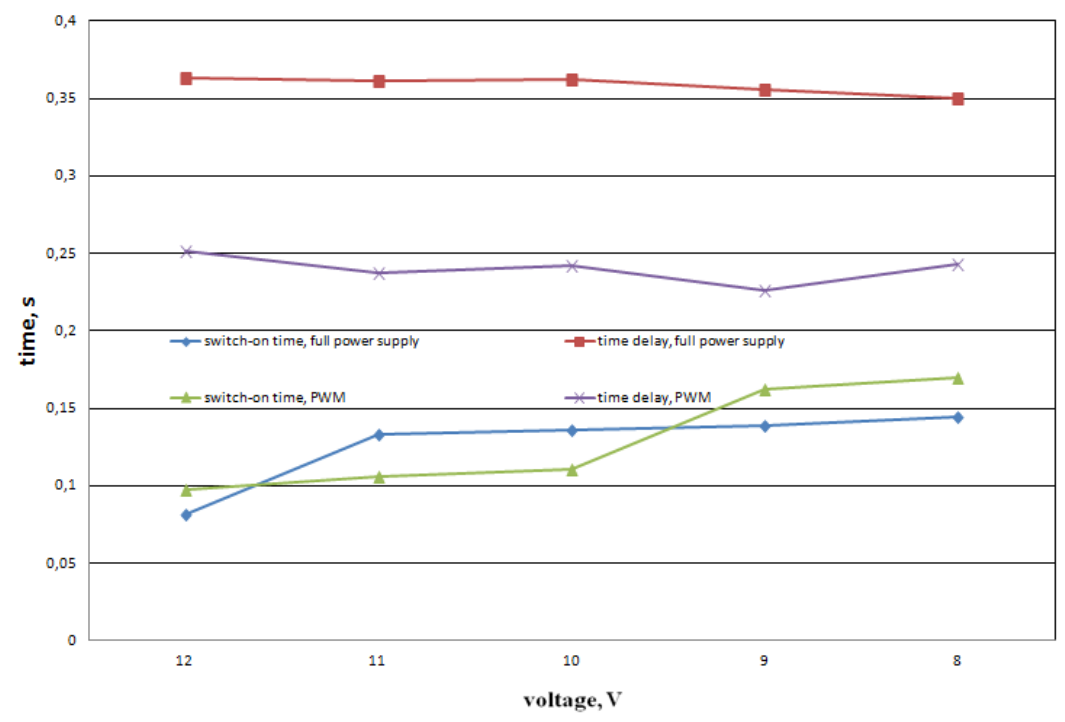

Fig. 3. Switching on and lag times with the PWM and full signal for sliding down mode depending on the different power source

Table 1

The switch-on time and the time lag of the leg sliding down function depending on the different power source

\begin{tabular}{|c|c|c|}
\hline Voltage [V] & Switch on speed [sec] & Time lag [sec] \\
\hline \multicolumn{3}{|c|}{ FULL POWER SUPPLY } \\
\hline 12 & 0.105031 & 0.295611 \\
\hline 11 & 0.123393 & 0.294231 \\
\hline 9 & 0.139552 & 0.278103 \\
\hline 8 & 0.158649 & 0.270531 \\
\hline \multicolumn{3}{|c|}{0.179949} \\
\\
\hline 12 & PMW POWER SUPPLY & 0.263096 \\
\hline 11 & 0.124245 & 0.289384 \\
\hline 10 & 0.125321 & 0.280281 \\
\hline 9 & 0.132207 & 0.263564 \\
\hline 8 & 0.159236 & 0.2515 \\
\hline
\end{tabular}




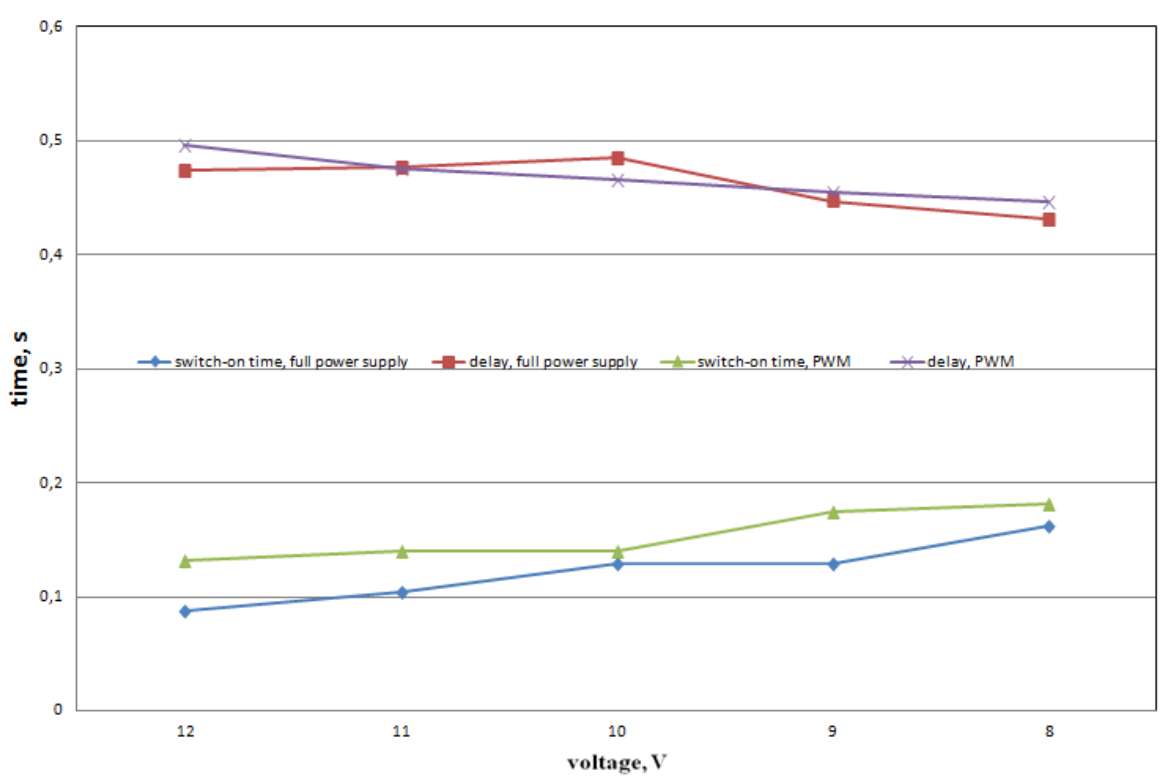

Fig. 4. Period of switching on and powering off the PWM and full signal for sliding out mode depending on the different power source

Table 2

The switch-on time and the time lag of the leg sliding down function

\begin{tabular}{|c|c|c|}
\hline \multicolumn{2}{|c|}{ Soltage [V] } & FULL POWER SUPPLY \\
\hline \multicolumn{3}{|c|}{ Time lag [sec] } \\
\hline 12 & 0.087404 & 0.32254 \\
\hline 11 & 0.104664 & 0.370331 \\
\hline 10 & 0.128535 & 0.327071 \\
\hline 9 & 0.129453 & 0.307621 \\
\hline 8 & 0.161954 & 0.29427 \\
\hline \multicolumn{3}{|c|}{ PMW POWER SUPPLY } \\
\hline 11 & 0.132207 & 0.32498 \\
\hline 10 & 0.140455 & 0.315023 \\
\hline 9 & 0.140455 & 0.310134 \\
\hline 8 & 0.17444 & 0.305877 \\
\hline
\end{tabular}

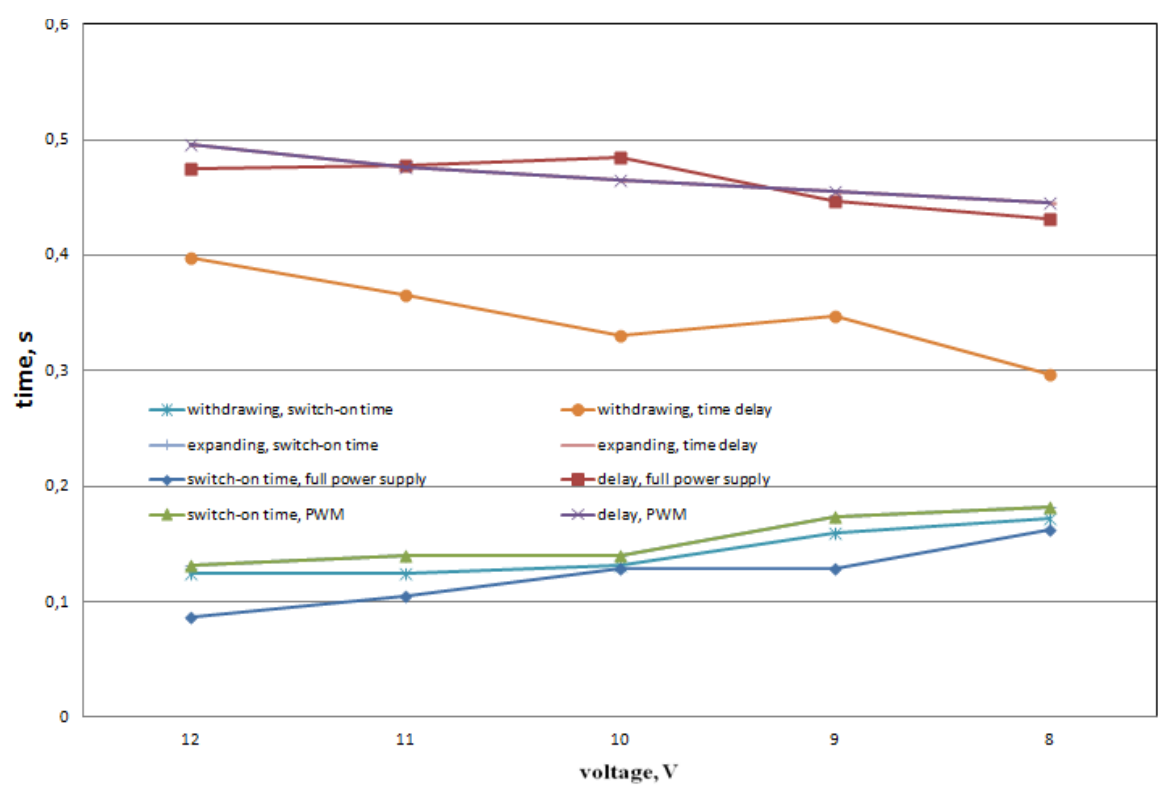

Fig. 5. Comparison of times for sliding out and down the legs, full power supply 
Table 3

Results of time comparisons for sliding down and out the legs at full power supply

\begin{tabular}{|c|c|c|}
\hline Voltage [V] & Switch on speed [sec] & Time lag [sec] \\
\hline \multicolumn{3}{|c|}{ Sliding down } \\
\hline 12 & 0.105031 & 0.295611 \\
\hline 11 & 0.123393 & 0.294231 \\
\hline 10 & 0.139552 & 0.278103 \\
\hline 9 & 0.158649 & 0.270531 \\
\hline 8 & 0.179949 & 0.263096 \\
\hline \multicolumn{3}{|c|}{ Sliding out } \\
\hline 11 & 0.087404 & 0.32254 \\
\hline 10 & 0.104664 & 0.370331 \\
\hline 9 & 0.128535 & 0.327071 \\
\hline 8 & 0.129453 & 0.307621 \\
\hline
\end{tabular}

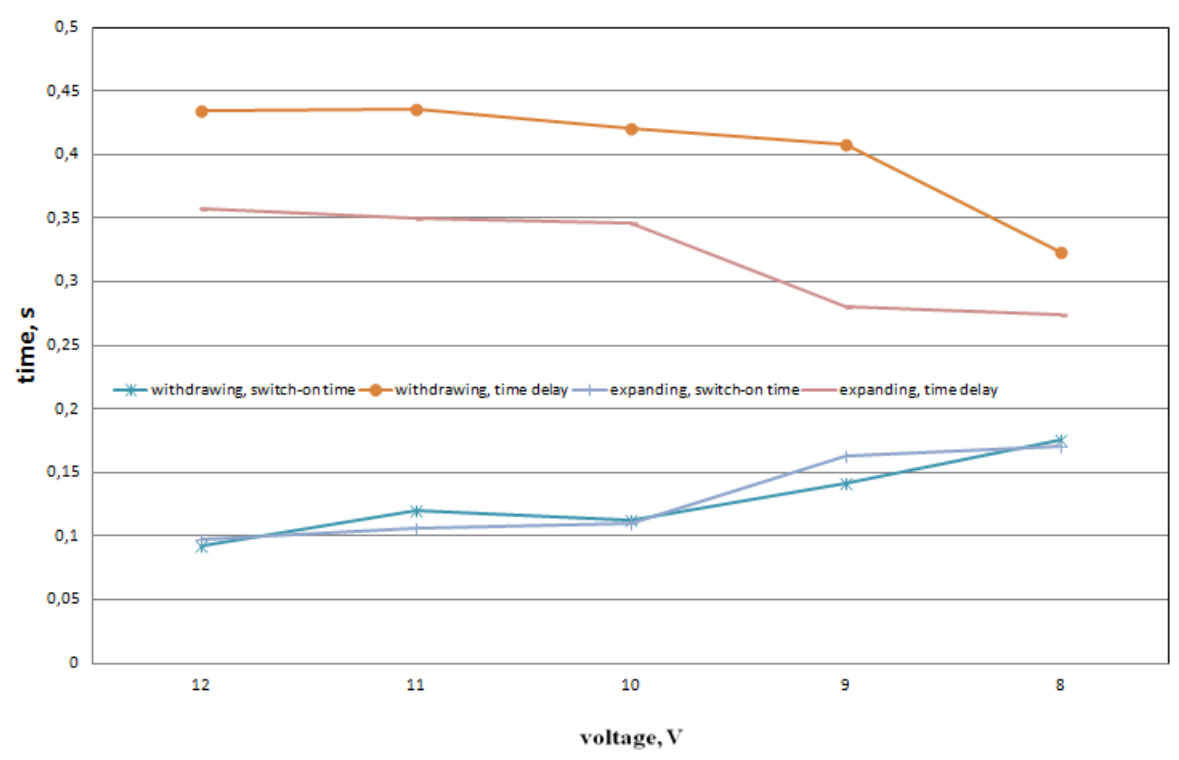

Fig. 6. Comparison of times for sliding out and down the legs, PWM power supply

Table 4

Results of time comparisons for sliding down and out the legs at full PWM

\begin{tabular}{|c|c|c|}
\hline Voltage [V] & Switch on speed [sec] & Time lag [sec] \\
\hline \multicolumn{3}{|c|}{ Sliding down } \\
\hline 12 & 0.124245 & 0.289384 \\
\hline 11 & 0.125321 & 0.280281 \\
\hline 10 & 0.132207 & 0.263564 \\
\hline 9 & 0.159236 & 0.2515 \\
\hline 8 & 0.172186 & 0.239014 \\
\hline \multicolumn{3}{|c|}{ Sliding out } \\
\hline 12 & 0.132207 & 0.32498 \\
\hline 11 & 0.140455 & 0.315023 \\
\hline 10 & 0.140455 & 0.310134 \\
\hline 9 & 0.17444 & 0.305877 \\
\hline 8 & 0.181784 & 0.27426 \\
\hline
\end{tabular}




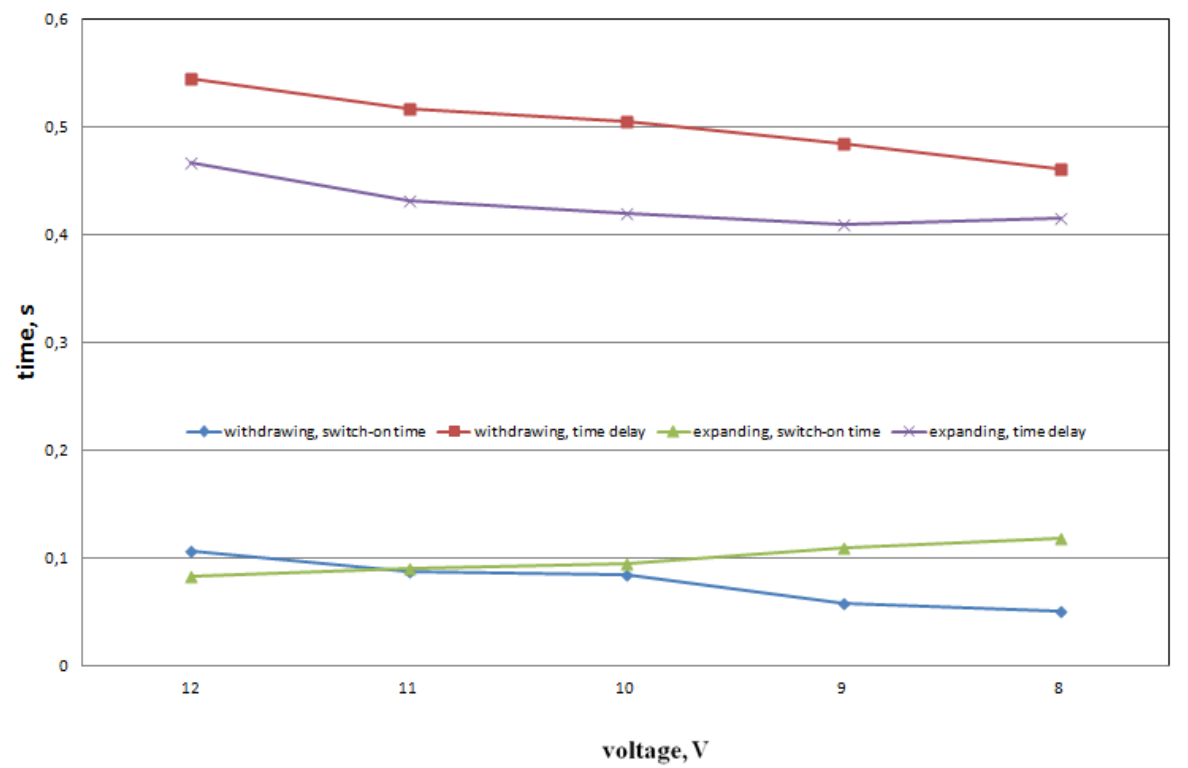

Fig. 7. Tests results for sliding down and up the canopy support's actuator depending on the different power source

Table 5

Results of time comparisons for sliding down and out the canopy's support depending on the different power source

\begin{tabular}{|c|c|c|}
\hline Voltage [V] & Switch on speed [sec] & Time lag [sec] \\
\hline \multicolumn{3}{|c|}{ Sliding down } \\
\hline 12 & 0.088689 & 0.409291 \\
\hline 11 & 0.092545 & 0.378858 \\
\hline 10 & 0.124862 & 0.302309 \\
\hline 9 & 0.118619 & 0.311947 \\
\hline 8 & 0.161954 & 0.292141 \\
\hline 12 & Sliding out \\
\hline 11 & 0.092545 & 0.274066 \\
\hline 10 & 0.102828 & 0.269387 \\
\hline 9 & 0.122292 & 0.253141 \\
\hline 8 & 0.142123 & 0.255114 \\
\hline
\end{tabular}

On the basis of the conducted tests, it can be stated that the lower the valve supply voltage, the longer the switching on time, whereas the lower the valve supply voltage, the shorter the delay time. Delay times for PWM signal and full power supply are comparable. An extremely important advantage of electrohydraulic control is the possibility of applying distributors with various nominal sizes. This allows to adjust the size of the distributors to the absorbency of the chambers of a given actuator, and thus to shorten the time of its overdriving. This is important in the case of sections equipped with large diameter legs. When using an innovative electrohydraulic control is it crucial to remembered that each control system must be made individually. It is therefore necessary to take into account both the design of the section, the number and size of hydraulic actuators and the control functions resulting from the suggestions of the future control user and the mining and geological conditions prevailing on the given mining wall.

\section{CONCLUSION}

The research presented in this work is one of the first ones on such an advanced control system in Poland. The developed design and the results obtained indicate large development opportunities in this area. What is more, the market of powered complexes 
shows a great interest in this type of solutions. Obtained results unambiguously indicate that the developed controller has very good working parameters. Response times are very low which ensures fast and reliable execution of tasks that the support has to perform. The modular construction of the control and executive blocks and the ergonomic control system mean that the entire system is very employee friendly. At the same time, it enables the implementation of virtually unlimited number of control functions. Its modular structure and versatility are its additional advantages.

A very important advantage of the developed system and the controller itself is that it can work without major modifications with other systems, including systems that record the machine operation parameters of the entire complex (Brodny et al., 2017; Brodny et al., 2017a; Brodny et al., 2017b) and with information platforms (Stecuła et al., 2017a; Stecuła et al., 2017b), enabling full visualization, monitoring and more advanced analyses of the entire system. This is particularly important for the entire company management system as well as control and supervision over the operation carried out. It also enables quick response to observed irregularities. In this respect, ergonomic elements and ease of use of the system for employees were also taken into account. The research conducted in the mines proves that one of the most serious problems for the staff is the complexity of systems that must be operated by employees and the lack or low level of training in this area (Palka et al., 2017a; Palka et al., 2017b). The constructors try to take into account and eliminate or limit the negative impact all the factors and possible problems.

It should also be emphasized that the presented solution fits very well into the idea of an intelligent mine and industry 4.0. There is, therefore, a good chance to put it into practice. This in turn should improve and facilitate the entire mining operation process and improve its economic efficiency.

\section{ACKNOWLEDGEMENTS}

The work was carried out within the project "Innovative electrohydraulic control system for powered roof support". POIR. 01.01.01-00-1129/15. The Operational Programme Smart Growth $2014-2020$ carried out by the National Centre for Research and Development.

\section{REFERENCES}

Brodny, J. and Tutak, M. (2018). Determination of the Zone with a Particularly High Risk of Endogenous Fires in the Goaves of a Longwall with Caving. Journal of Applied Fluid Mechanics, Vol. 11, No. 3, pp. 545-553. DOI: 10.18869/acadpub.jafm.73.246.27240.

Brodny, J., Tutak, M. and John, A. (2018). Analysis of influence of types of rocks forming the goaf with caving on the physical parameters of air stream flowing through these gob and adjacent headings. Mechanika, vol. $24 \mathrm{nr}$ 1, pp. 43-49, DOI 10.5755/j01.mech.24.1.20214.

Brodny, J., Alszer, S., Krystek, J. and Tutak, M. (2017). Availability analysis of selected mining machinery. Archives of Control Sciences Volume 27, No. 2, pp. 197-209.

Brodny, J., Tutak, M. and Michalak, M. (2017a). The use of the TGŚP module as a database to identify breaks in the work of mining machinery. BDAS 2017, Beyond Databases, Architectures and Structures. Towards Efficient Solutions for Data Analysis and Knowledge Representation. pp.441-452. DOI: 10.1007/978-3-319-58274-0 35.

Brodny, J., Tutak, M. and Michalak, M. (2017b). A Data Warehouse as an Indispensable Tool to Determine the Effectiveness of the Use of the Longwall Shearer. BDAS 2017. Beyond Databases, Architectures and Structures. Towards Efficient Solutions for Data Analysis and Knowledge Representation. pp.453-465. DOI: 10.1007/978-3-319-58274-0_36.

Brodny, J. and Tutak, M. (2016). Analysis of Methane Hazard Conditions in Mine Headings. Tehnički vjesnik - Technical Gazette, Vol.25 No.1 February 2018. pp. 271-276 https://doi.org/10.17559/TV-2016032219481.

Felka, D. and Brodny, J. (2018). Application of neural-fuzzy system in prediction of methane hazard. The First International Conference on Intelligent Systems in Production Engineering and Maintenance ISPEM 2017 pp.151-160. DOI 10.1007/978-3-319-64465-3_15.

Palka, D., Brodny, J. and Stecula, K. (2017a). Modern means of production and the staff awareness of the technical in the plant of the mining industry. CBU International Conference Proceedings 2017: Innovations in Science and Education, Vol. 5, Prague, p. 1190-1194. DOI: 10.12955/cbup.v5.1094. 
Palka, D., Hąbek, P. and Brodny, J. (2017b). Analysis of impact of OHS training quality on knowledge of workers in mining companies in the field of occupational safety. 17th International Multidisciplinary Scientific GeoConference SGEM 2017, www.sgem.org, SGEM2017 Conference Proceedings, ISBN 978-619-7105-00-1 / ISSN 1314-2704, 29 June - 5 July, 2017, Vol. 17, Issue 13, 61-68 pp, DOI: 10.5593/sgem2017/13/S03.009.

Stecuła, K., Brodny, J. and Tutak, M. (2017a). Informatics platform as a tool supporting research regarding the effectiveness of the mining machines' work. CBU International Conference Proceedings 2017: Innovations in Science and Education, Vol. 5, Prague 2017, p. 1215-1219. DOI 10.12955/cbup.v5.1099.

Stecuła, K., Brodny, J. and Tutak, M. (2017b). Use of intelligent informatics module for registration and assessment of causes of breaks in selected mining machines. The First International Conference on Intelligent Systems in Production Engineering and Maintenance ISPEM 2017, Advances in Intelligent Systems and Computing, pp.74-84.DOI 10.1007/978-3-319-64465-3_8.

Szurgacz, D. and Brodny, J. (2018). Analysis of rock mass dynamic impact influence on the operation of a powered roof support control system. E3S Web Conferences Volume 29, 2018, pp. E3S Web of Conferences elSSN: 2267-1242 https://doi.org/10.1051/e3sconf/20182900006.

Szurgacz, D. and Brodny, J. (2017). An innovative system to test components of mining machinery control hydraulics. $17^{\text {th }}$ International multidisciplinary scientific geo conference SGEM 2017, Volume 17. Science and technologies in geology, Exploration and Mining Issue 13. pp. 47-54, https://doi.org/10.5593/sgem2017/13/S03.007

Tutak, M. and Brodny, J.(2018). Impact of type of the roof rocks on location and range of endoge-nous fires particular hazard zone by in goaf with caving. E3S Web Conferences Volume 29, https://doi.org/10.1051/e3sconf/20182900005

Tutak, M. (2017). Assessment of hydrodynamics of gas flow through the porous rock structures. 17th International Multidisciplinary Scientific GeoConference SGEM 2017, SGEM2017 Vienna GREEN Vol. 17, Issue 15, 53-60 pp; DOI: 10.5593/sgem2017H/15/S06.007.

Tutak, M. and Brodny J. (2017a). Analysis of Influence of Goaf Sealing from Tailgate On the Me-thane Concentration at the Outlet from the Longwall. IOP Conf. Series: Earth and Envi-ronmental Science 95042025 doi :10.1088/1755-1315/95/4/042025.

Tutak, M. and Brodny J. (2017b). Determination of Particular Endogenous Fires Hazard Zones in Goaf with Caving of Longwall. IOP Conf. Series: Earth and Environmental Science 95 (2017) 042026 doi:10.1088/1755-1315/95/4/042026. 